\title{
ANÁLISE CLIMÁTICA DOS EPISÓDIOS DE ESTIAGEM QUE PROVOCARAM DANOS SOCIOECONÔMICOS NO OESTE CATARINENSE ENTRE 1999 A 2012
}

\author{
SPINELLI, Katia - kageografia@gmail.com \\ Centro Universitário Leonardo Da Vinci/ UNIASSELVI \\ NASCIMENTO, Rosemy - rosemy.nascimento@gmail.com \\ Universidade Federal de Santa Catarina / UFSC \\ FUENTES, Márcia - marciavfuentes@gmail.com \\ Instituto Federal de Santa Catarina / IFSC
}

\begin{abstract}
RESUMO: A Região Sul do Brasil, apesar de apresentar um clima subtropical úmido, com maior regularidade pluviométrica em comparação ao restante das regiões brasileiras, apresenta alguns períodos de estiagem que geram desastres socioambientais. Neste contexto, o objetivo do presente artigo é analisar os períodos de estiagem que ocasionaram danos socioeconômicos no Oeste Catarinense, assim como os sistemas e fenômenos atmosféricos que favoreceram a ocorrência desses períodos. O período de análise das estiagens foi entre 1999 a 2012. Utilizou-se o método dos quantis para classificar a chuva mensal e diária. Posteriormente, identificou-se a atuação dos fenômenos e sistemas atmosféricos que favoreceram os períodos com estiagem. A análise e discussão dos dados demonstrou que a redução mensal da pluviosidade entre os meses de novembro a abril ocasionou danos socioeconômicos na Região Oeste catarinense. Esses períodos de estiagem foram favorecidos pela influência de fenômenos e sistemas atmosféricos que, por vezes, atuaram em conjunto, como: Zona de Convergência do Atlântico Sul, Oscilação Decadal do Pacífico, La Niña e Oscilação Antártica.
\end{abstract}

PALAVRAS-CHAVe: Estiagem; Oeste catarinense; Fenômenos atmosféricos

ANALYZE THE DROUGHT PERIODS THAT HAVE CAUSED SOCIAL AND ECONOMIC DAMAGE IN THE WEST OF SANTA CATARINA FROM 1999 TO 2012

ABSTRACT: The South Region of Brazil, despite the humid subtropical climate, with more regular rainfall than the other Brazilian regions, has some drought periods that generate social and environmental disasters. In this context, the objective of the article is to analyze the drought periods that have caused social and economic damage in the West of Santa Catarina, as well as the atmospheric systems and phenomenon that have contributed to the occurrence of these periods. The drought period analyzed was from 1999 to 2012. The quantis method was used to classify daily and monthly rainfall levels. Later, the performance of the atmospheric phenomenon and systems that have facilitated the drought periods has been identified. The data analysis and discussion has shown that the monthly reduction of rainfall levels between November and April caused social and economic damage in the West region of Santa Catarina. These drought periods were favored by the influence of atmospheric phenomenon and systems that sometimes have acted together: the South Atlantic Convergence Zone, the Pacific Decadal Oscillation, La Niña and the Antarctic Oscillation.

KEYWORDS: Drought; West of Santa Catarina; Atmospheric phenomenon.

\section{INTRODUÇÃO}

A seca é um fenômeno que ocorre em várias regiões do mundo e causa impactos econômicos e/ou sociais por afetar a disponibilidade de água. 
Diferentemente de outros desastres naturais, o termo "seca" não possui uma definição universal (Wilhite et al. 2005). Wilhite e Glantz (1985) apud Hisdal e Tallaksen (2000) encontraram mais de 150 definições de seca publicadas cientificamente, e que alguns fatores influenciam as diferentes definições de seca como a problemática da pesquisa, a disponibilidade de dados e as características climáticas locais e regionais.

A Região Sul do Brasil, apesar de apresentar um clima subtropical úmido, com maior regularidade pluviométrica em comparação ao restante das regiões brasileiras, apresenta alguns períodos de seca que geram desastres socioambientais. Devido às particularidades climáticas, vários pesquisadores brasileiros como Sacco (2010), Gonçalves et al. (2014), Doubrawa (2007) e Mendonça et al. (2005) utilizam o termo estiagem para caracterizar o período de seca na Região Sul do país. E, desta forma, optou-se por manter neste artigo essa denominação.

No entanto, o conceito de estiagem ainda não se definiu plenamente para a Região Sul do país. O conceito elaborado por Antônio Luiz Coimbra de Castro (1996) é o mais divulgado pela ciência. Para ele a estiagem ocorre quando o início da temporada chuvosa atrasa por quinze dias ou quando a média da precipitação mensal dos meses mais chuvosos alcançam limites inferiores a $60 \%$ das médias mensais de longo período. No entanto, esse conceito foi apresentado em um manual de desastres naturais da defesa civil de Santa Catarina, faltando rigor científico para confirmá-lo.

Desta forma, após revisão teórica sobre o conceito de seca e estiagem, considerou-se o conceito da Sociedade Meteorológica Americana - AMS (2013) em que a seca, diferentemente da aridez, ocorre em um determinado período e posteriormente as condições normais de precipitação voltam a ocorrer. A seca é mais do que simplesmente um déficit de precipitação, mas ela resulta de uma complexa interação entre fatores naturais e sociais. É resultado de interações entre deficiência de precipitação ou evapotranspiração excessiva durante um período de tempo, e, a demanda pelo uso da água que pode ser intensificada pela ineficiência de distribuição, planejamento e gestão da água. Desta forma, a seca é um evento prolongado, de uma deficiente acumulação de precipitação e abastecimento de água, seguido por impactos sociais e econômicos.

Assim, a estiagem no Sul do país é compreendida, neste artigo, como um período de redução nas condições normais da precipitação e/ou excessos de evapotranspiração que geram impactos socioeconômicos. É uma interação entre aspectos físicos locais/regionais e gestão do uso da água.

Em relação às pesquisas sobre a ocorrência de estiagens em Santa Catarina, Nimer (1979) já apontava a ocorrência de anos secos na Região Sul e seus impactos socioeconômicos desde 1917. Ele identificou que os anos de 1917, 1921, 1924 e 1933 apresentaram desvio negativo de precipitação, sendo que toda ou quase toda a Região Sul esteve sujeita à estiagem, que durou mais de três meses. Nimer (1979) salienta que os períodos secos trouxeram consequências graves à economia rural da região, que não estava preparada técnica e estruturalmente para enfrentar a falta de chuva.

Além dos períodos de seca definidos por Nimer (1979), Espíndola e Nodari (2012) descrevem que jornais catarinenses mais antigos apontavam problemas socioeconômicos causados pela falta de chuva entre os anos de 1948 
a 1951. Um exemplo foi o jornal O tempo, de 1950, que apontou os períodos de seca como uma das sete pragas da cidade de Concórdia, localizada no oeste catarinense.

Mais recentemente, o Atlas de Desastres Naturais de Santa Catarina, organizado por Herrmann (2014), identificou 1534 decretos municipais de Estado de Emergência e Calamidade Pública, provocados pela estiagem em Santa Catarina, entre 1980 a 2010. Tal pesquisa apontou que esses decretos municipais ocorrem anualmente de forma esporádica, sendo que os anos de 2004, 2005 e 2006 apresentaram os maiores registros de desastres. No entanto, em relação à sazonalidade houve uma concentração na ocorrência de desastres nos meses do outono e verão (Herrmann, 2014). Ressalta-se que o Atlas de Desastres Naturais de Santa Catarina, organizado por Herrmann (2014), não faz uma análise aprofundada sobre a estiagem no estado catarinense, traz uma análise inicial sobre a temática que lança possibilidade de futuros aprofundamentos teóricos.

Em nível de pós-graduação, a estiagem em Santa Catarina foi abordada na dissertação de Doubrawa (2007) e de Sacco (2010). Doubrawa (2007) descreve que as estiagens podem estar relacionadas com o uso intensivo do solo pelas atividades agropecuárias sem o uso de técnicas de conservação do solo e dos recursos hídricos, além disso, o adensamento da malha viária, urbana e agroindustrial favorecem o escoamento superficial da água no solo e o desabastecimento das nascentes. Isso faz com que a demanda por recursos hídricos aumente e favoreça a instalação da crise por falta de água. Enquanto que Sacco (2010) abordou as estiagens com um viés meteorológico. A autora utilizou o mesmo critério de Castro (1996), mencionado anteriormente, para identificar os períodos de estiagem no oeste catarinense. Visto que, durante o período de 2001 a 2006, identificou 12 eventos de estiagem. Ressalta-se que Sacco (2010) não relacionou os períodos de estiagem com o registro de ocorrência de desastres na região, ficou mais atenta à identificação dos períodos de estiagem a partir de um conceito que considera somente a redução da precipitação.

Diante disso, há uma lacuna no conhecimento científico sobre quais períodos com déficit de precipitação são capazes de provocar impactos socioeconômicos na Região Oeste catarinense, pois se considera, de acordo com Armond (2014), que há diferença entre eventos extremos e episódios extremos. De modo que, os eventos extremos são valores de chuva que extrapolam os valores habituais climaticamente e assim se pode dizer que são os "eventos meteorológicos". Enquanto os episódios extremos são aqueles que, além de extrapolarem os valores habituais, repercutem em um impacto social. Assim, nem todo o evento extremo provoca um dano material e/ou imaterial.

Acerca dos fenômenos e sistemas atmosféricos que provocam as estiagens, algumas pesquisas como a de Sacco (2010), Gonçalves et al. (2014) e Mendonça et al. (2005) apontam influências da La Niña, dos bloqueios atmosféricos e da atuação das Zonas de Convergência do Atlântico Sul.

Além desses fenômenos e sistemas atmosféricos outros como a Oscilação Decadal do Pacífico (ODP) e a Oscilação Antártica (AAO) são capazes de interferir na redução no regime de precipitação na Região Sul. 
Rebello (2006), Cera et al. (2009) e Streck et al. (2009) encontram influência da fase fria da ODP na redução de chuvas para a Região Sul. Enquanto que as pesquisas de Santos e Francos (2010) e Oliveira (2011) encontraram relação entre a fase negativa da AAO e a redução de chuvas. No entanto, tais pesquisas não tiveram o objetivo de identificar a influência desses fenômenos especificamente para os períodos de estiagem, carecendo de análise.

Diante desse contexto, o objetivo deste artigo é analisar climaticamente os períodos de estiagem que ocasionaram danos socioeconômicos no oeste catarinense, assim como os sistemas e fenômenos atmosféricos que favoreceram a ocorrência desses períodos.

O recorte espacial da pesquisa foi composto por quatro microrregiões, definidas pelo IBGE: São Miguel do Oeste, Chapecó, Concórdia e Xanxerê. Elas são as microrregiões mais atingidas por desastres decorrentes da estiagem no estado catarinense, conforme se verificou em Herrmann (2014). Assim, esse recorte espacial foi denominado de Região Oeste. A Figura 1 demonstra a localização da área de estudos.

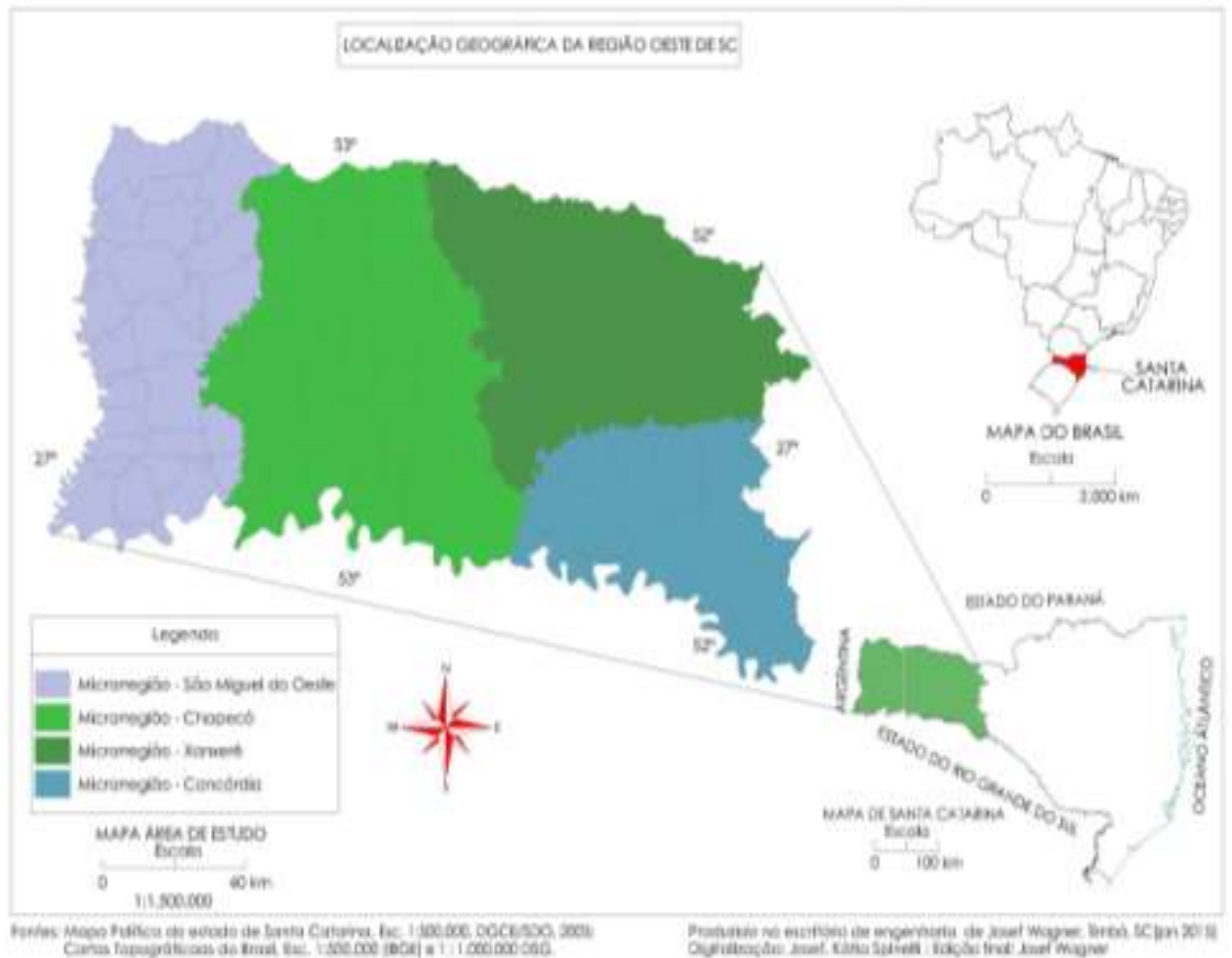

Figura 1 - Mapa de localização da área de pesquisa - Região Oeste. Fonte: SPINELLI (2018).

Tal pesquisa busca contribuir teoricamente com os fatores que interferem na formação de episódios de estiagem que provocam danos socioeconômicos a Região Oeste. De acordo com Spinelli (2018), tais episódios afetam principalmente a população rural que é atingida pela perda da produtividade agropecuária. Contudo, também provoca redução na produção de energia das hidroelétricas instaladas na região, redução na distribuição da água para a zona urbana e, problemas na saúde pública devido ao consumo de água imprópria. 
Entende-se que esta pesquisa possa contribuir para caracterização da dimensão física acerca das estiagens. Visto que sobre o prisma da dimensão física dos desastres naturais, há quatro parâmetros que a caracterizam: a) Mecanismos físicos (Magnitude, duração, extensão espacial); b) Distribuição temporal (frequência, sazonalidade, período de retorno); c) Distribuição espacial (Localização geográfica); d) Dinâmica de eclosão (rapidez do início e rapidez do término) (Mattedi; Butzke, 2001).

Nesse sentido, a pesquisa contribui na identificação da duração, sazonalidade e dinâmica de eclosão dos períodos de estiagem que provocam riscos socioeconômicos à Região Oeste. Além disso, busca identificar os fenômenos atmosféricos capazes de favorecer a redução no regime pluviométrico. Tais contribuições teóricas são relevantes à previsão e gestão de ocorrência de um desastre.

Este artigo está estruturado em quatro sessões: a primeira aborda a ocorrência dos períodos de estiagem em Santa Catarina, a partir da revisão bibliográfica; a segunda demonstra os procedimentos metodológicos da pesquisa; a terceira apresenta os resultados alcançados e a última sessão descreve as considerações finais.

\section{EPISÓDIOS DE ESTIAGEM EM SANTA CATARINA: IMPACTOS E CONDIÇÕES ATMOSFÉRICAS}

Os períodos de estiagem que ocorrem em Santa Catarina, por vezes, ocasionam danos materiais e imateriais. O setor mais atingido é a agropecuária, sobretudo, com perdas na produção de grãos, como o milho, a soja e o feijão. $\mathrm{Na}$ pecuária o produto mais afetado é a produção do leite. Além disso, a estiagem já comprometeu a distribuição de água na zona urbana e rural, ocasionou diminuição da energia nas hidroelétricas e, gerou problemas na saúde pública provocados pelo consumo de água impotável (SPINELLI, 2018).

Herrmann e Alves (2014) aponta que entre 2000 a 2010 as estiagens em Santa Catarina provocaram prejuízos econômicos que ultrapassaram 4 bilhões de reais. Sendo que, os anos de maiores perdas financeiras foram os de 2007 e 2008 com aproximadamente um bilhão setecentos e sete milhões de reais e dois bilhões cento e treze milhões de reais, respectivamente.

O Atlas de Desastres Naturais de Santa Catarina, organizado por Herrmann (2014), apresenta um levantamento e análise dos decretos de emergência e calamidade pública das prefeituras catarinenses devido a eventos de desastres naturais, de 1980 a 2010. Entre esse período totalizaram-se 1534 decretos provocados pela estiagem em Santa Catarina. O Quadro 1 mostra os anos, os meses e a quantidade de municípios que registraram desastre provocado pela estiagem em Santa Catarina. 
Quadro 1 - Número de municípios que registraram desastre causado pela estiagem

\begin{tabular}{|c|c|c|c|}
\hline Ano & $\begin{array}{l}\text { Número de } \\
\text { ocorrência } \\
\text { por } \\
\text { município }\end{array}$ & Meses de ocorrência & $\begin{array}{c}\text { Meses com maior } \\
\text { ocorrência por municípios }\end{array}$ \\
\hline 1987 & 6 & nov /dez & \\
\hline 1988 & 90 & jun/jul/set/out & jul \\
\hline 1990 & 71 & dez & \\
\hline 1991 & 10 & jan & \\
\hline 1992 & 2 & jan/dez & \\
\hline 1993 & 3 & dez & \\
\hline 1994 & 6 & jan/fev/set & \\
\hline 1995 & 27 & out/ nov/dez & Dez \\
\hline 1996 & 20 & jan/mar/maio & Jan \\
\hline 1997 & 36 & $\mathrm{fev} / \mathrm{mar} / \mathrm{abr} / \mathrm{maio}$ & Maio \\
\hline 1998 & 8 & dez & \\
\hline 1999 & 52 & maio/set/nov/dez & Maio \\
\hline 2000 & 31 & jan/mar/abr/jun & Jan \\
\hline 2001 & 1 & dez & \\
\hline 2002 & 107 & $\mathrm{jan} / \mathrm{fev} / \mathrm{mar} / \mathrm{abr}$ & Jan \\
\hline 2003 & 22 & fev/abr/maio/jun/ago/set/dez & \\
\hline 2004 & 189 & $\mathrm{jan} / \mathrm{fev} / \mathrm{mar} / \mathrm{abr} / \mathrm{maio} / \mathrm{dez}$ & fev/mar/abr \\
\hline 2005 & 294 & $\mathrm{jan} / \mathrm{fev} / \mathrm{mar} / \mathrm{abr} / \mathrm{maio} / \mathrm{dez}$ & $\mathrm{fev} / \mathrm{mar} / \mathrm{abr}$ \\
\hline 2006 & 189 & jan/fev/mar/abr/maio/jun/jul/set/nov & jan/maio \\
\hline 2007 & 1 & fev & \\
\hline 2008 & 116 & jan/fev/mar/abr/jun/out/nov/dez & abr/nov/dez \\
\hline 2009 & 254 & jan/fev/mar/abr/maio/jun/jul/set/nov & abr/ maio \\
\hline 2010 & 1 & set & \\
\hline
\end{tabular}

Fonte: Herrmann (2014), adaptado por Kátia Spinelli (2018).

Através do Quadro 1 se pode verificar que a maior quantidade de decretos foi registrada entre os anos de 2004 e 2009, com a maior ocorrência em 2005. Anterior a este período, os anos de 1998, 1990 e 2002 também se sobressaíram aos demais. Em alguns anos os registros ocorreram todos em um ou três meses, já em outros, observam-se que os decretos ocorreram em quase todos os meses do ano. Este fato pode ser um indício de que a estiagem não tem um comportamento único em todos os anos.

Mensalmente, a maior frequência de registro de calamidade pública ou estado de emergência em eventos de estiagem ocorreu de dezembro a maio, sendo que janeiro teve o maior registro. Diante disso, percebe-se que as estiagens no estado catarinense ocorrem anualmente de forma esporádica, contudo sazonalmente há uma concentração no verão e outono.

O Atlas de Desastres Naturais do Estado de Santa Catarina - período de 1980 a 2010 (Herrmann, 2014) também demonstrou a frequência dos registros de estiagem por município. A Região Oeste catarinense apresenta a maior concentração de registro de desastres por estiagem. Nessa região se localizam os dez municípios mais atingidos por danos socioeconômicos decorrentes da estiagem. Em ordem decrescente os municípios são: Coronel Freitas, Presidente Castelo Branco, Itá, Itapiranga, Anchieta, Seara, Xaxim, Ipira, Japorá e Planalto 
Alegre. Além desses, mais 31 municípios do oeste catarinense foram classificados por uma frequência muito alta de decretos por estiagem.

Ressalta-se que a Região Oeste catarinense possui como principal fonte econômica o setor agroindustrial e as atividades agropecuárias são as mais impactadas pelos períodos de estiagem. Visto que, as outras regiões do estado catarinense possuem outros setores econômicos como principal fonte de renda e, consequentemente são menos afetadas pelos impactos econômicos decorrentes da estiagem.

Sacco (2010), em sua pesquisa de mestrado, utilizou o mesmo critério da defesa civil (Castro, 1996) para identificar os períodos de estiagem no oeste catarinense. Durante o período de 2001 a 2006, Sacco identificou 12 eventos de estiagem que podem ser visualizados no Quadro 2.

Ressalta-se que diferentemente de Herrmann (2014), Sacco (2010) não analisou a ocorrência de desastres devido à estiagem, visto que sua pesquisa teve um viés meteorológico.

Quadro 2 - Eventos de estiagem no oeste catarinense no período de 2001 a 2006.

\begin{tabular}{|c|c|}
\hline Evento & Período \\
\hline 1 & Julho a agosto de 2001 \\
\hline 2 & Outubro de 2001 \\
\hline 3 & Dezembro de 2001 a abril de 2002 \\
\hline 4 & Julho de 2002 \\
\hline 5 & Maio a setembro de 2003 \\
\hline 6 & Janeiro a abril de 2004 \\
\hline 7 & Junho a agosto de 2004 \\
\hline 8 & Maio a agosto de 2005 \\
\hline 9 & Maio a julho de 2006 \\
\hline 10 & Oovembro de 2006 \\
\hline 11 & \\
\hline
\end{tabular}

Fonte: Sacco (2010).

Neste quadro, observa-se que no ano de 2001 as estiagens ocorreram em julho, agosto, outubro e dezembro. No ano de 2002, a situação se agrava, e a estiagem se estende de janeiro a abril e, novamente em julho. Em 2003, os eventos de estiagem ocorreram entre maio a setembro. Já em 2004, o evento ocorreu em três períodos intercalados de: janeiro a abril, de junho a agosto, e, de novembro a dezembro. Este último se estendeu até março do ano seguinte. Em 2005 novamente houve três períodos de estiagem: janeiro a março, maio a agosto, e, novembro a dezembro, novamente se estendendo até o próximo ano. O ano de 2006 teve, assim como os anteriores, nove meses com chuvas irregulares, sendo que a estiagem ocorreu entre: janeiro a fevereiro, abril a julho, e, outubro a dezembro (Sacco, 2010).

A partir desses resultados, Sacco (2010) concluiu que a estiagem é um fenômeno meteorológico que pode ocorrer em qualquer estação do ano provocado por configuração da circulação atmosférica, capazes de reduzir a pluviosidade.

Diante disso, é primordial o entendimento dos fenômenos meteorológicos que são capazes de produzir períodos sem ou com pouca precipitação. Perante as pesquisas até então realizadas sobre estiagem na região Sul, aponta-se para 
os eventos de La Niña, bloqueios atmosféricos e a atuação conjunta entre ZCAS e mTc como causadores dos eventos de estiagem. Contudo, outros sistemas podem favorecer redução nos volumes de precipitação, mas que ainda não foram relacionados às estiagens no oeste, como a Oscilação Decadal do Pacífico e a Oscilação Antártica.

Mendes et al. (2005) apontou que a ocorrência de bloqueios atmosféricos pode causar períodos de veranicos (dias sem chuva e com alta temperatura) para o sul do Brasil. Em concordância, Sacco (2010) identificou que os bloqueios atmosféricos tiveram uma influência significativa na ocorrência de estiagem na Região Oeste catarinense, sendo que eles atuaram em $50 \%$ dos episódios de estiagem entre 2001 a 2006. Além disso, verificou que os bloqueios ocorreram com maior frequência no Oceano Pacífico $e$, que o número de bloqueios durante o inverno foi superior às demais estações.

Mendonça et al. (2005) pesquisaram os sistemas atmosféricos que atuaram nos episódios de estiagem na bacia do Rio Araranguá, que se localiza no sul de Santa Catarina, no período de 2001 a 2004. Identificaram a atuação dos bloqueios atmosféricos e da La Ninã nos períodos de estiagem. Além disso, os autores indicaram a possível influência da Zona de Convergência do Atlântico Sul (ZCAS) e da massa tropical continental (mTc) na ocorrência de estiagem na Região Sul.

Pesquisas como a de Cataldi et al. (2010) e Marengo et al. (2009) demonstram que a formação da ZCAS, principalmente se o seu posicionamento for sobre o Oceano Atlântico, favorece dias consecutivos mais secos na Região Sul do Brasil. Isso ocorre porque há um enfraquecimento dos jatos de baixos níveis direcionados ao sul do país, provocado pelo direcionamento da umidade da Amazônia para o sudeste do país durante os episódios de ZCAS. Além disso, as ZCAS impactam a formação dos Complexos Convectivos de Mesoescalas (CCM) durante os meses de primavera, que são os principais sistemas que favorecerem ocorrência de chuva nessa época do ano para Região Sul.

A formação das ZCAS, também, gera um movimento de subsidência do ar sobre a Região Sul, o que impacta a formação das chuvas durante o verão. Já que nessa estação do ano grande parte da chuva é formada por convecção e, o movimento de subsidência gerado desfavorece esse tipo de precipitação. Aliado a isso, nessa época do ano, a mTc (Massa Tropical Continental) é atuante na Região Oeste, o que contribuiu para manter o ar seco e quente (Carvalho; Jones, 2009; Mendonça et al., 2005).

Os fenômenos ENOS e ODP atuam em grande escala e podem favorecer a ocorrência de períodos secos na Região Sul do país. Seus impactos podem ocorrer de ordem mensal, sazonal, anual e interdecenal (Cavalcanti; Ambrizzi, 2009). Esses fenômenos exercem teleconexões com a América do Sul e consequentemente, com o Brasil. Tanto o ENOS como a ODP são fenômenos definidos por anomalias na Temperatura da Superfície do Mar (TSM), que acarretam em grandes variações nos fluxos da interface oceano-atmosfera, e, consequentemente nos sistemas atmosféricos que modificam as condições de tempo.

Para a Região Sul do país, o ENOS favorece períodos de chuva intensa, durante sua fase quente, de El Niño. Enquanto que, durante sua fase fria, de La Niña, favorece a redução da precipitação. Grimm (2009) salienta que durante a 
primavera há maior influência do ENOS para a Região Sul. Enquanto que, Minuzzi (2010) aponta que em Santa Catarina os meses de outubro e novembro são os mais impactados pela redução das chuvas sobre influência de La Niña.

Ressalta-se que a pesquisa de Ashok et al (2007) apresentou um diferente tipo de ENOS chamado de Modoki. Referente a anomalia de TSM que ocorre no Pacífico Central acompanhada por anomalias contrárias de TSM no Pacífico Leste e Oeste. Tedechi e Cavalcanti (2010), indicaram que a região Sul do país apresentou durante o verão, uma diminuição na precipitação em períodos de La Niña Canônico (convencional) e Modoki.

Em contradição, Minuzzi (2018), ao pesquisar sobre a variabilidade da precipitação em Santa Catarina durante os tipos de ENOS, não encontrou diferença entre a ocorrência de períodos secos durante ENOS Canônico e Modoki em relação aos anos neutros. Diante disso, é relevante que novas pesquisas contribuam com essas análises.

Pesquisas como a de Cera, Ferraz e Bender (2009), Streck et al. (2009) e Prestes et al. (2010) verificaram que as anomalias negativas da ODP favorecem períodos mais secos na Região Sul e, assim, podem favorecer a ocorrência de estiagens na Região Oeste. De acordo com Kayano e Andreoli (2007), o ENOS e a ODP podem atuar juntos intensificando ou enfraquecendo os efeitos provocados pelo El Niño e La Niña. Dessa forma, quando ocorrerem conjuntamente, anomalias negativas da ODP e do ENOS (La Niña) podem ocasionar períodos de estiagem na Região Oeste.

Além desses dois fenômenos de grande escala, a AAO também é capaz de interferir nas condições do tempo no Hemisfério Sul. Pesquisas como a de Silvestri e Vera (2009) e Santos e Franco (2010) demonstram que a fase positiva da AAO favorece a formação da ZCAS e de bloqueios atmosféricos, consequentemente condições de estiagem na Região Sul do país. Oliveira (2011) e Vasconcelos e Cavalcanti (2010) encontraram relação entre a redução de chuva na Região Sul com o índice positivo da AAO.

\section{PROCEDIMENTOS METODOLÓGICOS}

Nesta pesquisa utilizou-se o método quantitativo. Foram realizados procedimentos metodológicos para determinar a ocorrência dos desastres por estiagem, a análise da precipitação e a verificação dos sistemas e fenômenos atmosféricos que favoreceram os períodos de estiagem.

Neste artigo, buscou identificar os períodos de estiagem que causaram danos socioeconômicos na Região Oeste para a partir deles realizar a análise da precipitação. Porém não foi alvo desta pesquisa analisar os impactos materiais e imateriais provocados pela estiagem.

Partiu-se do princípio de que os períodos de estiagem que provocaram danos socioeconômicos na região tiveram registros na defesa civil e, ocasionaram decretos de Estado de Emergência (SE) ou Estado de Calamidade Pública $(E C P)^{1}$. Dessa forma, verificou-se os decretos municipais de SE e ECP

\footnotetext{
${ }^{1} \mathrm{O}$ decreto $\mathrm{n}^{\circ} 7257$ de 4 de agosto de 2010 define que a situação de emergência é uma situação anormal, provocada por desastre, causando danos e prejuízos que impedem o comprometimento parcial da capacidade de resposta do poder público do ente atingido. Enquanto a Calamidade pública
} 
decorrentes de estiagem registrados pelos municípios que compõem a região pesquisada.

Os decretos estão disponíveis no site da Defesa Civil de Santa Catarina, somente a partir de 1997. Visto que, a partir dessa data, os decretos de desastres por estiagem foram registrados em maior quantidade somente no ano de 1999. Com isso, elegeu-se como período de análise os anos de 1999 a 2012.

Após identificar os períodos com ocorrência de desastres por estiagem, buscou-se analisar a variabilidade diária e mensal da chuva. Optou-se por trabalhar com a análise mensal e diária da chuva, pois Spinelli (2018) demonstrou que os dados anuais não são suficientes para explicar a ocorrência de desastres por estiagem na região. Já que anos com chuva acima da média e dentro da normalidade também apresentaram registros de decretos municipais de Estado de Emergência e Calamidade Pública decorrentes da estiagem.

Os dados de chuva são provenientes de dezoito estações meteorológicas da área de estudos. Os dados referem-se ao período de 1980 a 2012, pertinente para aplicar uma análise estatística e verificar os períodos com chuva abaixo da normalidade. A Figura 2 demonstra a localização das estações meteorológicas utilizadas na pesquisa.

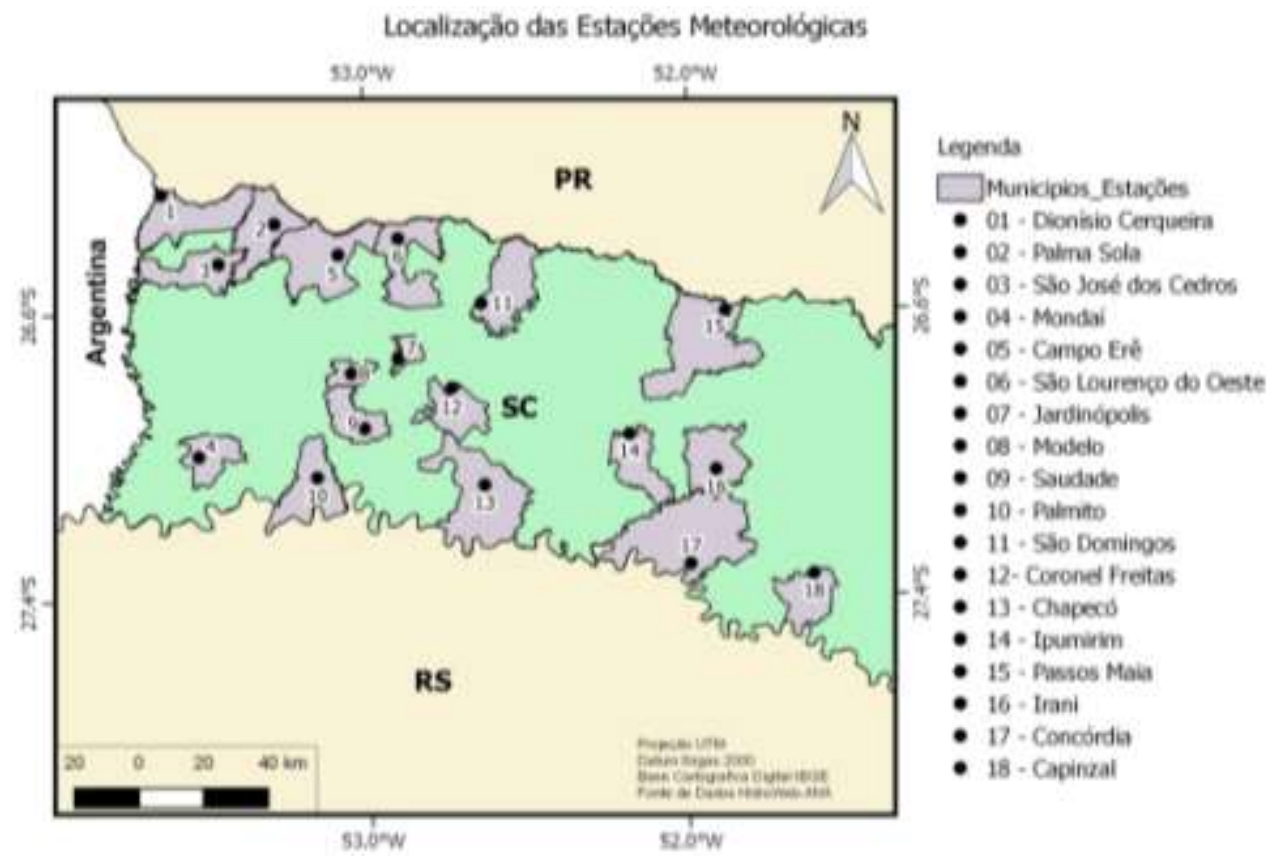

Figura 2 - Localização das estações meteorológicas utilizadas nas pesquisas. Elaboração: Alexandre Schweitze e Kátia Spinelli. Fonte: Spinelli (2018).

Dos dados selecionados para a análise, verificou-se que ocorriam falhas na ordem de 3 a $20 \%$ do período selecionados. Desta forma, optou-se por preencher os dados faltantes. Como em muitas estações meteorológicas ocorreram falhas nos mesmos meses e anos, não seria viável aplicar a técnica da média ponderada entre as estações vizinhas, e, assim utilizou-se um

é uma situação anormal, provocada por desastre, causando danos e prejuízos que impedem o comprometimento substancial da capacidade de resposta do poder público do ente atingido. 
conjunto de dados do CPC (Climate Prediction Center) para realizar o preenchimento.

Posteriormente, os dados das chuvas mensais e diárias foram analisados através da técnica dos quantis, sendo possível, assim, identificar os períodos mais secos na região e, relacioná-los com os períodos em que ocorreram desastres por estiagem.

Em relação à análise das chuvas mensais, elas foram classificadas em meses: extremamente seco, muito seco, seco, normal, chuvoso, muito chuvoso ou extremamente chuvoso. Aplicaram-se as seguintes ordens quantílicas: $p=0,05 ; p=0,15 ; p=0,35 ; p=0,65 ; p=0,85 ; p=0,95 ;$ considerou-se a pesquisa de Sena et al. (2014). Esta ordem quantílica utilizada teve o objetivo de definir os extremos de precipitação.

Já as chuvas diárias foram analisadas de acordo com a quantidade de dias com chuva durante o mês. Utilizou-se a técnica dos quantis, na ordem quantílica estabelecida por Xavier e Xavier (1999), em que: $p=0,15 ; p=0,35$; $p=0,65 ; p=0,85$. Com as seguintes denominações: muito poucos dias com chuva; poucos dias com chuva; normal; frequentes dias com chuva; muito frequentes dias com chuva.

Em sequência, relacionaram-se os períodos com registro de desastres por estiagem e as condições de chuva mensal e diária deste período. Assim, foi possível verificar as condições pluviométricas que favoreceram a ocorrência de estiagem na região.

Para a análise dos sistemas atmosféricos que possibilitam a redução das chuvas na região, foram selecionados os meses em que houve predomínio de chuvas abaixo da média entre as estações meteorológicas da região e, a ocorrência de desastres. Teve como base os períodos que apresentaram pelo menos $50 \%$ das estações meteorológicas com chuvas mensais e/ou diárias abaixo da normalidade de acordo com a técnica dos quantis.

Analisou-se a atuação dos seguintes fenômenos e sistemas: ZCAS, sistemas frontais, ENOS, ODP e AAO, utilizando o Boletim da Climanálise para identificar os episódios da ZCAS.

A cronologia de ocorrência de ENOS foi utilizada a partir do índice ONI (Oceanic Niño Index) disponível no Nacional Oceanic and Atmospheric Administration (NOAA). Esse índice se baseia numa média de 30 anos da Temperatura da Superfície do Mar (TSM) na região do Pacífico localizada a $5^{\circ} \mathrm{N}$ $5^{\circ} \mathrm{S}$ e $120^{\circ}-170^{\circ} \mathrm{W}$ (EI Niño 3.4). Além disso, utilizou-se a cronologia do ENOS Canônico e Modoki apresentada por Minuzzi (2018) que utilizou o método de Yeh et al (2009).

Para verificar a atuação da ODP, se utilizou o Índice da Oscilação Decadal do Pacífico (IODP), que está disponível no Joint Institute for the Study of the Atmosphere and Ocean (JISAO).

Também, foi utilizado o índice que avalia a Oscilação Antártica que está disponível no Climate Prediction Center (CPC) do NOAA. O índice calcula a média diária e mensal derivada das anomalias geopotencial em $700 \mathrm{hPa}$ entre $20^{\circ} \mathrm{a}$ $90^{\circ}$ de latitude sul. 


\section{EPISÓDIOS DE ESTIAGEM COM DANOS SOCIOECONÔMICOS NA REGIÃO OESTE: RESULTADOS E DISCUSSÃO}

A Figura 3 demonstra os anos em que foram registrados decretos municipais de Estado de Emergência e de Calamidade Pública, devido à estiagem, nos municípios pertencentes à região de estudos. E, visualiza-se que os anos de 1999, 2000, 2002, 2004, 2005, 2006, 2008, 2009, 2011 e 2012 apresentaram registros de desastres por estiagem. O ano com maior registro de decretos foi o de 2005, com 126 decretos. Seguidos pelo ano 2009 com 89 decretos, e, o ano de 2002 e 2004 com 88.

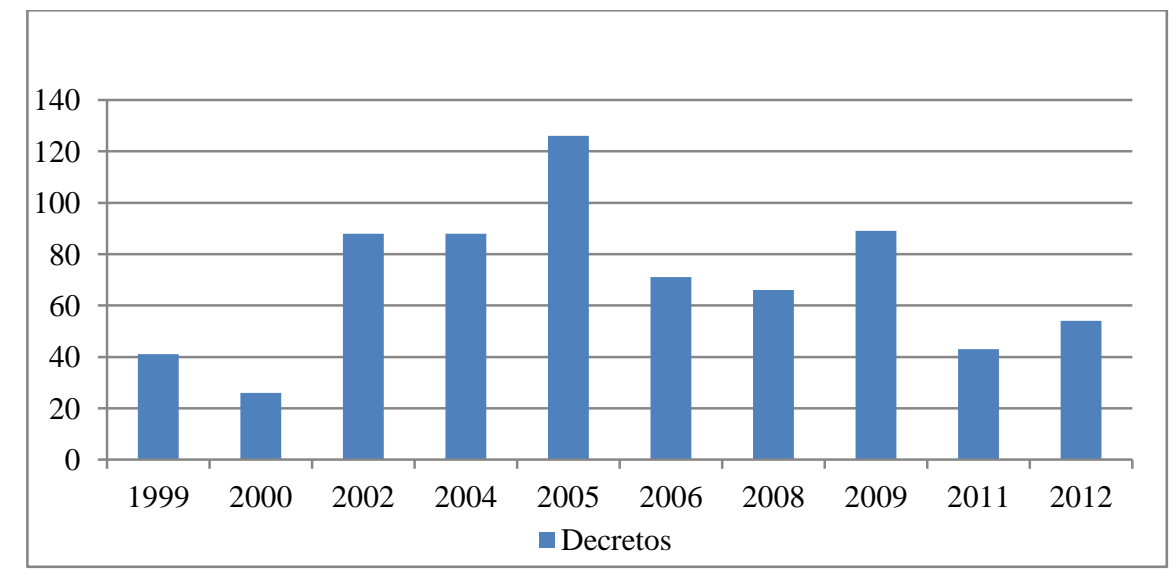

Figura 3 - Quantidade de decretos municipais de Estado de Emergência e Calamidade Pública por estiagem no Oeste Catarinense, no período de 1999 a 2012. Fonte: Defesa Civil de Santa Catarina. Elaboração: Spinelli (2018).

Mensalmente, os maiores registros de decretos por desastres devido à estiagem ocorreram de dezembro a março, com ênfase no mês de janeiro em que se registraram 216 decretos entre o período de 1999-2000. A Figura 4 demonstra a distribuição mensal do registro do desastre.

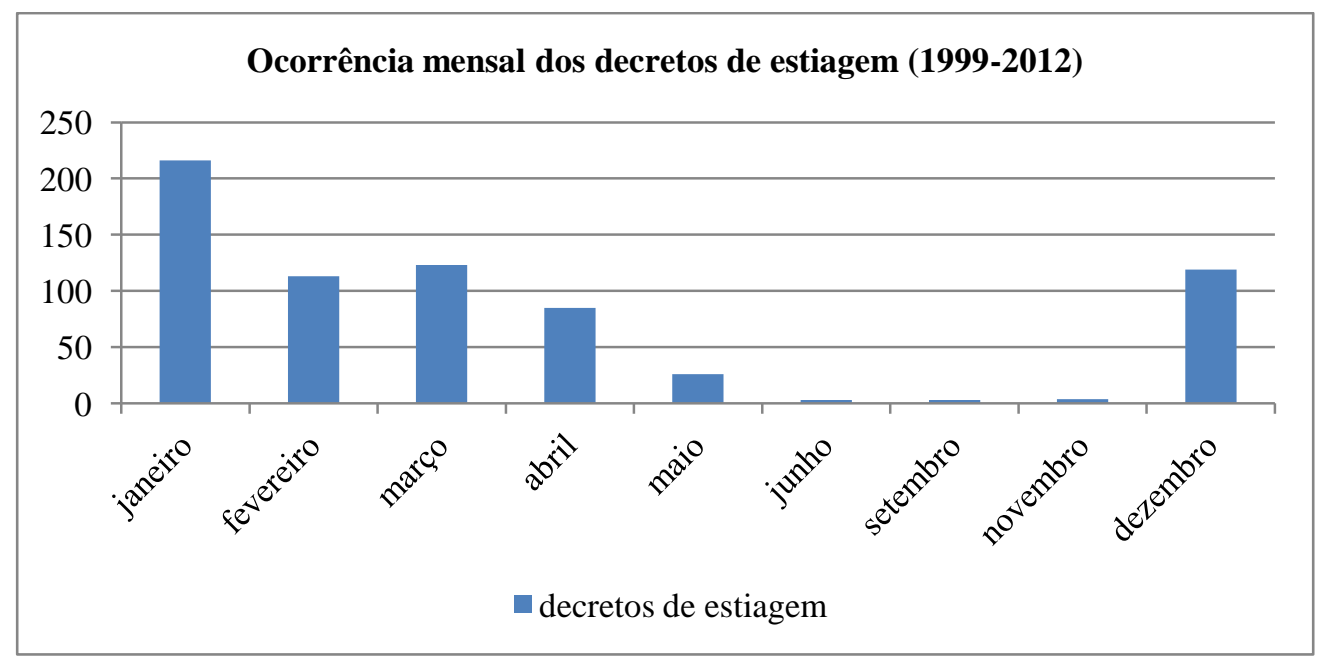

Figura 4 - Ocorrência mensal dos decretos municipais por estiagem, no período de 1999 a 2012 no Oeste Catarinense. Fonte: Defesa Civil de Santa Catarina. Elaboração: Spinelli (2018). 
De acordo com Spinelli (2018) os principais danos decorrentes da estiagem na Região Oeste são: a queda acentuada na produção da agropecuária, diminuição na produção de energia em hidroelétrica, racionamento de água na zona rural e urbana, e, um aumento de pessoas que apresentaram problemas de saúde, devido ao consumo de água impotável. Além disso, a estiagem causa danos em "efeito cascata", pois as perdas na agropecuária provocam prejuízos em outros serviços do ramo, como: feiras e comércios de serviços coloniais, feiras do gado e indústrias de beneficiamento.

A produção de grãos (milho, soja e feijão) é a mais afetada em períodos de estiagem. Sendo que a de milho apresenta maiores perdas, em decorrência disso, ocorre à elevação do preço do produto o que impacta o custo da produção de outros setores, como a suinocultura, avicultura e bovinocultura (SPINELLI, 2018).

\subsection{ANÁlise CLIMÁtica dOS EPISÓdios DE ESTIAgEM QUE FAVORECERAM DANOS SOCIOECONÔMICOS}

A partir do registro mensal dos decretos, verificaram-se a pluviosidade mensal e diária, assim como os fenômenos atmosféricos, conforme descritos na metodologia. Diante disso, o Quadro 3 demostra os meses que apresentaram redução no volume de chuva em pelo menos $50 \%$ das estações meteorológicas da região e que resultaram no registro de desastres por estiagem. Além de, apresentar a quantidade de episódios de ZCAS que ocorreram em um mês, o fenômeno ENOS, o índice da ODP e da AAO.

Quadro 3 - Análise climática dos episódios com estiagem na Região Oeste catarinense.

\begin{tabular}{|c|c|c|c|c|c|c|}
\hline Mês/ano & Pluviosidade & $\begin{array}{l}\text { Episódios } \\
\text { de ZCAS }\end{array}$ & $\begin{array}{l}\text { ENOS } \\
\text { (ONI) }\end{array}$ & $\begin{array}{c}\text { ENOS } \\
\text { Canônico } \\
\text { ou } \\
\text { Modoki }\end{array}$ & ODP & AAO \\
\hline Nov/98 & $\begin{array}{l}\text { Mês seco, muito seco ou } \\
\text { extremamente seco. } \\
\text { Houve poucos ou muito } \\
\text { poucos dias com chuva. }\end{array}$ & 1 & La Niña & $\begin{array}{l}\text { La Niña } \\
\text { Modoki }\end{array}$ & $-0,52$ & 0,87 \\
\hline Mar/99 & $\begin{array}{l}\text { Mês seco, muito seco ou } \\
\text { extremamente seco. } \\
\text { Houve poucos ou muito } \\
\text { poucos dias com chuva. }\end{array}$ & 0 & La Niña & $\begin{array}{l}\text { La Niña } \\
\text { Modoki }\end{array}$ & $-0,33$ & 0,18 \\
\hline Nov/99 & $\begin{array}{l}\text { Mês seco, muito seco ou } \\
\text { extremamente seco. } \\
\text { Houve poucos ou muito } \\
\text { poucos dias com chuva. }\end{array}$ & 2 & La Niña & $\begin{array}{l}\text { La Niña } \\
\text { Canônico }\end{array}$ & $-2,05$ & 0,90 \\
\hline Dez/99 & $\begin{array}{c}\text { Dias com chuva } \\
\text { concentrados na primeira } \\
\text { quinzena do mês, o que } \\
\text { causou um reduzido } \\
\text { volume de chuva na } \\
\text { segunda quinzena do } \\
\text { mês. } \\
\end{array}$ & 2 & La Niña & $\begin{array}{l}\text { La Niña } \\
\text { Canônico }\end{array}$ & $-1,63$ & 1,78 \\
\hline Dez/2001 & $\begin{array}{l}\text { Mês seco ou muito seco. } \\
\text { Houve poucos ou muito } \\
\text { poucos dias com chuva. }\end{array}$ & 2 & Neutro & Neutro & 0,52 & 1,47 \\
\hline Fev/2002 & Mês seco e muito seco. & 2 & Neutro & El Niño & $-0,64$ & 1,33 \\
\hline
\end{tabular}




\begin{tabular}{|c|c|c|c|c|c|c|}
\hline & $\begin{array}{l}\text { Houve poucos ou muito } \\
\text { poucos dias com chuva. }\end{array}$ & & & Modoki & & \\
\hline Mar/2002 & Mês seco e muito seco. & 0 & Neutro & $\begin{array}{l}\text { El Niño } \\
\text { Modoki }\end{array}$ & $-0,43$ & $-1,82$ \\
\hline Abr/2002 & $\begin{array}{l}\text { Mês seco, muito seco e } \\
\text { extremamente seco. }\end{array}$ & 0 & Neutro & $\begin{array}{l}\text { El Niño } \\
\text { Modoki }\end{array}$ & $-0,32$ & 0,165 \\
\hline Fev/2004 & $\begin{array}{l}\text { Mês seco, muito seco ou } \\
\text { extremamente seco. } \\
\text { Houve poucos ou muito } \\
\text { poucos dias com chuva. }\end{array}$ & 2 & Neutro & Neutro & 0,48 & $-1,18$ \\
\hline Mar/2004 & $\begin{array}{l}\text { Mês seco, muito seco ou } \\
\text { extremamente seco. } \\
\text { Houve poucos ou muito } \\
\text { poucos dias com chuva. }\end{array}$ & 0 & Neutro & Neutro & 0,61 & 0,43 \\
\hline Dez/2004 & $\begin{array}{l}\text { Mês seco, muito seco e } \\
\text { extremamente seco. } \\
\text { Muito poucos e poucos } \\
\text { dias com chuva. }\end{array}$ & 2 & El Niño & $\begin{array}{l}\text { El Niño } \\
\text { Modoki }\end{array}$ & $-0,17$ & $-0,97$ \\
\hline Fev/2005 & $\begin{array}{c}\text { Mês muito seco e } \\
\text { extremamente seco. } \\
\text { Muito poucos dias com } \\
\text { chuva. }\end{array}$ & 1 & Neutro & $\begin{array}{l}\text { El Niño } \\
\text { Modoki }\end{array}$ & 0,81 & $-1,24$ \\
\hline Mar/2005 & $\begin{array}{l}\text { Mês seco e muito seco. } \\
\text { Muito poucos e poucos } \\
\text { dias com chuva. }\end{array}$ & 2 & El Niño & $\begin{array}{l}\text { El Niño } \\
\text { Modoki }\end{array}$ & 1,36 & 0,15 \\
\hline Nov/2005 & $\begin{array}{l}\text { Mês seco e muito seco. } \\
\text { Muito poucos e poucos } \\
\text { dias com chuva. }\end{array}$ & 3 & La Niña & Neutro & $-1,50$ & $-0,55$ \\
\hline Dez/2005 & $\begin{array}{l}\text { Mês seco, muito seco e } \\
\text { extremamente seco. } \\
\text { Poucos e muito poucos } \\
\text { dias com chuva. }\end{array}$ & 2 & La Niña & Neutro & 0,20 & $-1,9$ \\
\hline Jan/2006 & $\begin{array}{l}\text { Maior volume de chuva } \\
\text { concentrada na segunda } \\
\text { quinzena do mês, } \\
\text { permanecendo os } \\
\text { primeiros } 15 \text { dias do mês } \\
\text { com um volume de } \\
\text { chuva reduzido. }\end{array}$ & 2 & La Niña & Neutro & 1,03 & 0,33 \\
\hline Fev/2006 & Mês seco e muito seco. & 2 & La Niña & Neutro & 0,66 & $-0,21$ \\
\hline Abr/2006 & $\begin{array}{l}\text { Mês seco, muito seco e } \\
\text { extremamente seco. } \\
\text { Poucos e muito poucos } \\
\text { dias com chuva. }\end{array}$ & 0 & Neutro & Neutro & 0,40 & $-0,16$ \\
\hline Fev/2008 & $\begin{array}{l}\text { Mês seco, muito seco ou } \\
\text { extremamente seco. }\end{array}$ & 3 & La Niña & $\begin{array}{l}\text { La Niña } \\
\text { Modoki }\end{array}$ & $-0,77$ & 1,14 \\
\hline Mar/2008 & $\begin{array}{c}\text { Mês seco e muito seco, } \\
\text { com predomínio de } \\
\text { poucos e muito poucos } \\
\text { dias de chuva. }\end{array}$ & 2 & La Niña & $\begin{array}{l}\text { La Niña } \\
\text { Modoki }\end{array}$ & $-0,71$ & 0,58 \\
\hline Dez/2008 & $\begin{array}{l}\text { Mês seco e muito seco, } \\
\text { com poucos e muito } \\
\text { poucos dias com chuva. }\end{array}$ & 3 & La Niña & $\begin{array}{l}\text { La Niña } \\
\text { Modoki }\end{array}$ & $-0,87$ & 1,19 \\
\hline Fev/2009 & Mês seco e muito seco. & 1 & La Niña & $\begin{array}{l}\text { La Niña } \\
\text { Modoki }\end{array}$ & $-1,55$ & 0,45 \\
\hline Mar/2009 & Mês seco e muito seco, & 2 & La Niña & La Niña & $-1,59$ & 0,60 \\
\hline
\end{tabular}




\begin{tabular}{|c|c|c|c|c|c|c|}
\hline & $\begin{array}{c}\text { com poucos e muito } \\
\text { poucos dias com chuva. }\end{array}$ & & & Modoki & & \\
\hline Abr/2009 & $\begin{array}{c}\text { Mês seco, muito seco e } \\
\text { extremamente seco. } \\
\text { Houve muito poucos dias } \\
\text { com chuva }\end{array}$ & 1 & Neutro & $\begin{array}{c}\text { La Niña } \\
\text { Modoki }\end{array}$ & $-1,65$ & 0,02 \\
\hline Nov/2011 & $\begin{array}{c}\text { Mês seco e muito seco. } \\
\text { Houve pouco e muito } \\
\text { poucos dias com chuva. }\end{array}$ & 2 & La Niña & Neutro & $-2,33$ & $-0,90$ \\
\hline Jan/2012 & $\begin{array}{c}\text { Mês seco, muito seco e } \\
\text { extremamente seco. } \\
\text { Houve pouco e muito } \\
\text { poucos dias com chuva. } \\
\begin{array}{c}\text { Mês seco, muito seco e } \\
\text { extremamente seco. } \\
\text { Com predomínio de } \\
\text { poucos e muito poucos } \\
\text { dias com chuva. }\end{array}\end{array}$ & 3 & La Niña & Neutro & $-1,38$ & 1,58 \\
\hline Mar/2012 & $\begin{array}{c}\text { Mês seco, muito seco e } \\
\text { extremamente seco. } \\
\text { Houve poucos e muito } \\
\text { poucos dias com chuva. }\end{array}$ & 1 & La Niña & Neutro & $-1,05$ & 0,2 \\
$\begin{array}{c}\text { Seco, muito seco e } \\
\text { extremamente seco, com } \\
\text { poucos e muito poucos } \\
\text { dias de chuva. }\end{array}$ & 3 & Neutro & Neutro & $-0,59$ & $-1,70$ \\
\hline Nov/2012 & & & & 2,57 \\
\hline
\end{tabular}

Fonte: próprio autor.

Ressalta-se que o registro de decretos de Estado de Emergência e Calamidade Pública decorrentes da estiagem ocorreu no mesmo mês que houve as condições de estiagem, ou após um ou dois meses com redução das chuvas. A análise dos dados demonstrados no Quadro 3 é realizada a seguir nos subtítulos 4.1.1 e 4.1.2.

\subsubsection{CONDIÇÕES DE ESTIAGEM: REDUÇÃO DA PLUVIOSIDADE MENSAL E DIÁRIA}

As condições de estiagem que se repetiram entre os meses analisados foram de chuva mensal abaixo da normalidade, configurando-se em meses secos, muito secos ou extremamente secos; aliados a poucos ou muito poucos dias com chuva, conforme demonstrado no Quadro 3. As tabelas 1 e 2 demonstram os limiares da chuva mensal e diária entre as estações meteorológicas.

A Tabela 1 mostra os valores definidos pela técnica dos quantis para classificar os valores da chuva mensal em extremamente seco (ES), muito seco (MS), seco (S), normal (N), chuvoso (C), muito chuvoso (MC) e extremamente chuvoso (EC). E a tabela 2, demonstra a quantidade de dias com chuva classificados em: muito poucos dias (MP), poucos dias (P), normal (N), frequentes (F) e muito frequentes (MF). 
Tabela 1 - Valores dos Quantis (Q0,05; Q0,15; Q0,35; Q0,65; Q0,85; Q0,95) para a chuva mensal (mm) na Região Oeste.

\begin{tabular}{|c|c|c|c|c|c|c|c|}
\hline $\begin{array}{c}\text { Estação } \\
\text { meteorológica }\end{array}$ & ES & MS & $\mathbf{S}$ & $\mathbf{N}$ & $\mathbf{C}$ & MC & EC \\
\hline $\begin{array}{l}\text { Dionísio } \\
\text { Cerqueira }\end{array}$ & $x \leq 25,9$ & $\begin{array}{c}25,9< \\
x \leq 63,7\end{array}$ & $\begin{array}{l}63,7<X \\
\leq 127,8\end{array}$ & $\begin{array}{c}127,8< \\
X \leq \\
210,2\end{array}$ & $\begin{array}{c}210,2< \\
X \leq \\
299,2\end{array}$ & $\begin{array}{c}299,2<X \leq \\
388,8\end{array}$ & $x>388,8$ \\
\hline Palma Sola & $x \leq 28,8$ & $\begin{array}{c}28,8< \\
x \leq 71,6\end{array}$ & $\begin{array}{c}71,6<X \leq \\
119,8\end{array}$ & $\begin{array}{c}119,8< \\
X \leq \\
202,7\end{array}$ & $\begin{array}{l}202,7< \\
x \leq 293\end{array}$ & $\begin{array}{c}293<X \leq \\
394,4\end{array}$ & $x>394,4$ \\
\hline $\begin{array}{l}\text { São José dos } \\
\text { Cedros }\end{array}$ & $x \leq 34,6$ & $\begin{array}{c}34,6< \\
x \leq 68,6 \\
\end{array}$ & $\begin{array}{c}68,6<X \\
\leq 121,9\end{array}$ & $\begin{array}{c}121,9< \\
x \leq 203,3\end{array}$ & $\begin{array}{c}203,3< \\
x \leq 288,2 \\
\end{array}$ & $\begin{array}{c}288,2<X \\
\leq 373,8\end{array}$ & $x>373,8$ \\
\hline Mondaí & $x \leq 41,5$ & $\begin{array}{c}41,5< \\
x \leq 75,6\end{array}$ & $\begin{array}{c}75,6< \\
x \leq 123,3\end{array}$ & $\begin{array}{l}123,3< \\
X \leq 196,4\end{array}$ & $\begin{array}{l}196,4< \\
X \leq 275,1\end{array}$ & $\begin{array}{c}275,1< \\
X \leq 378\end{array}$ & $x>378$ \\
\hline Campo Erê & $x \leq 30,5$ & $\begin{array}{c}30,5< \\
x \leq 66,4\end{array}$ & $\begin{array}{c}66,4< \\
x \leq 116,1\end{array}$ & $\begin{array}{l}116,1< \\
X \leq 181,3\end{array}$ & $\begin{array}{l}181,3< \\
X \leq 266,2\end{array}$ & $\begin{array}{l}266,2< \\
X \leq 358,4\end{array}$ & $x>358,4$ \\
\hline $\begin{array}{c}\text { São Lourenço } \\
\text { do Oeste }\end{array}$ & $x \leq 36,6$ & $\begin{array}{l}36,6< \\
x \leq 71\end{array}$ & $\begin{array}{c}71< \\
x \leq 123,1\end{array}$ & $\begin{array}{c}123,1< \\
x \leq 197,9\end{array}$ & $\begin{array}{c}197,9< \\
X \leq 275,9\end{array}$ & $\begin{array}{c}275,9< \\
x \leq 390,4\end{array}$ & $x>390,4$ \\
\hline Jardinópolis & $x \leq 34,9$ & $\begin{array}{c}34,9< \\
X \leq 68,9\end{array}$ & $\begin{array}{c}68,9< \\
x \leq 116,1\end{array}$ & $\begin{array}{c}116,1< \\
X \leq 192,4\end{array}$ & $\begin{array}{c}192,4< \\
X \leq 252,4\end{array}$ & $\begin{array}{c}252,4< \\
X \leq 333,8\end{array}$ & $x>333,8$ \\
\hline Modelo & $x \leq 31,5$ & $\begin{array}{c}31,5< \\
x \leq 60,6\end{array}$ & $\begin{array}{c}60,6< \\
x \leq 112,2\end{array}$ & $\begin{array}{c}112,2< \\
x \leq 189,6\end{array}$ & $\begin{array}{c}189,6< \\
x \leq 265,8\end{array}$ & $\begin{array}{c}265,8< \\
x \leq 349,9\end{array}$ & $x>349,9$ \\
\hline Saudade & $x \leq 34$ & $\begin{array}{c}34<X \leq \\
64,7\end{array}$ & $\begin{array}{c}64,7< \\
x \leq 106,3\end{array}$ & $\begin{array}{l}106,3< \\
X \leq 179,8\end{array}$ & $\begin{array}{c}179,8< \\
x \leq 248,3\end{array}$ & $\begin{array}{c}248,3< \\
x \leq 339,5\end{array}$ & $x>339,5$ \\
\hline Palmito & $x \leq 32,9$ & $\begin{array}{c}32,9< \\
x \leq 66,8 \\
\end{array}$ & $\begin{array}{c}66,8< \\
x \leq 111,7 \\
\end{array}$ & $\begin{array}{c}111,7< \\
x \leq 176,9\end{array}$ & $\begin{array}{c}176,9< \\
x \leq 250,6\end{array}$ & $\begin{array}{c}250,6< \\
x \leq 329,3 \\
\end{array}$ & $x>329,3$ \\
\hline São Domingos & $x \leq 39,1$ & $\begin{array}{c}39,1< \\
x \leq 74,4\end{array}$ & $\begin{array}{c}74,4< \\
x \leq 114,1\end{array}$ & $\begin{array}{c}114,1< \\
x \leq 196,5\end{array}$ & $\begin{array}{c}196,5< \\
x \leq 279,4\end{array}$ & $\begin{array}{c}279,4< \\
x \leq 364,4\end{array}$ & $x>364,4$ \\
\hline $\begin{array}{l}\text { Coronel } \\
\text { Freitas }\end{array}$ & $x \leq 31,3$ & $\begin{array}{c}31,3< \\
x \leq 63,5\end{array}$ & $\begin{array}{c}63,5< \\
x \leq 106 \\
\end{array}$ & $\begin{array}{c}106<X \leq \\
181,6\end{array}$ & $\begin{array}{l}181,6<X \\
\leq 245,8\end{array}$ & $\begin{array}{c}245,8<X \\
\leq 322\end{array}$ & $x>322$ \\
\hline Chapecó & $x \leq 41,6$ & $\begin{array}{c}41,6< \\
x \leq 73,6\end{array}$ & $\begin{array}{c}73,6< \\
x \leq 118,4\end{array}$ & $\begin{array}{c}118,4< \\
X \leq 191,8\end{array}$ & $\begin{array}{c}191,8< \\
X \leq 264,4\end{array}$ & $\begin{array}{c}264,4< \\
x \leq 338,9\end{array}$ & $x>338,9$ \\
\hline Ipumirim & $x \leq 39,4$ & $\begin{array}{c}39,4< \\
x \leq 76,5 \\
\end{array}$ & $\begin{array}{l}76,5< \\
x \leq 118 \\
\end{array}$ & $\begin{array}{c}118< \\
x \leq 188,9\end{array}$ & $\begin{array}{c}188,9< \\
x \leq 259,5\end{array}$ & $\begin{array}{c}259,5< \\
x \leq 319,2 \\
\end{array}$ & $x>319,2$ \\
\hline Passos Maia & $x \leq 36,9$ & $\begin{array}{c}36,9< \\
x \leq 66,1\end{array}$ & $\begin{array}{c}66,1< \\
x \leq 109,6 \\
\end{array}$ & $\begin{array}{c}109,6< \\
x \leq 170,2\end{array}$ & $\begin{array}{c}170,2< \\
x \leq 251,7\end{array}$ & $\begin{array}{c}251,7< \\
x \leq 345,8 \\
\end{array}$ & $x>345,8$ \\
\hline Irani & $x \leq 45$ & $\begin{array}{c}45<X \leq \\
77,8\end{array}$ & $\begin{array}{c}77,8< \\
x \leq 126 \\
\end{array}$ & $\begin{array}{c}126<X \leq \\
192,2\end{array}$ & $\begin{array}{l}192,2<X \\
\leq 264,4\end{array}$ & $\begin{array}{c}264,4<X \leq \\
344,4\end{array}$ & $x>344,4$ \\
\hline Concórdia & $x \leq 44$ & $\begin{array}{c}44<X \leq \\
73,5\end{array}$ & $\begin{array}{c}73,5< \\
x \leq 116,7 \\
\end{array}$ & $\begin{array}{c}116,7< \\
x \leq 190,5\end{array}$ & $\begin{array}{c}190,5< \\
x \leq 244,6\end{array}$ & $\begin{array}{l}244,6< \\
X \leq 302 \\
\end{array}$ & $x>302$ \\
\hline Capinzal & $x \leq 38,3$ & $\begin{array}{c}38,3< \\
x \leq 69,2 \\
\end{array}$ & $\begin{array}{c}69,2< \\
x \leq 114,9 \\
\end{array}$ & $\begin{array}{c}114,9< \\
x \leq 171,3\end{array}$ & $\begin{array}{c}171,3< \\
x \leq 231,7\end{array}$ & $\begin{array}{c}231,7< \\
x \leq 295,2\end{array}$ & $x>295,2$ \\
\hline
\end{tabular}

Fonte: ANA. Elaboração: Kátia Spinelli (2018).

Tabela 2 - Valores dos Quantis (Q0,15; Q0,35; Q0,65; Q0,85) para classificação dos dias com chuva.

\begin{tabular}{cccccc}
\hline $\begin{array}{c}\text { Estação } \\
\text { meteorológica }\end{array}$ & MP & PD & N & F & MF \\
\hline $\begin{array}{c}\text { Dionísio } \\
\text { Cerqueira }\end{array}$ & $\mathrm{x} \leq 5$ & $5<\mathrm{X} \leq 8$ & $8<\mathrm{X} \leq 11$ & $\begin{array}{c}11<\mathrm{X} \leq \\
14\end{array}$ & $\mathrm{X}>14$ \\
\hline Palma Sola & $\mathrm{x} \leq 4$ & $4<\mathrm{X} \leq 6$ & $6<\mathrm{X} \leq 9$ & $9<\mathrm{X} \leq 11$ & $\mathrm{X}>11$ \\
\hline $\begin{array}{c}\text { São José dos } \\
\text { Cedros }\end{array}$ & $\mathrm{x} \leq 5$ & $5<\mathrm{X} \leq 7$ & $7<\mathrm{X} \leq 9$ & $9<\mathrm{X} \leq 12$ & $\mathrm{X}>12$ \\
\hline Mondaí & $\mathrm{x} \leq 6$ & $6<\mathrm{X} \leq 8$ & $8<\mathrm{X} \leq 10$ & $\begin{array}{c}10<\mathrm{X} \leq \\
13\end{array}$ & $\mathrm{X}>13$ \\
\hline Campo Erê & $\mathrm{x} \leq 5$ & $5<\mathrm{X} \leq 7$ & $7<\mathrm{X} \leq 10$ & $10<\mathrm{X} \leq$ & $\mathrm{X}>13$ \\
\hline
\end{tabular}




\begin{tabular}{cccccc}
\hline $\begin{array}{c}\text { São Lourenço } \\
\text { do Oeste }\end{array}$ & $\mathrm{x} \leq 6$ & $6<\mathrm{X} \leq 7$ & $7<\mathrm{X} \leq 10$ & $\begin{array}{c}10<\mathrm{X} \leq \\
13\end{array}$ & $\mathrm{X}>13$ \\
\hline Jardinópolis & $\mathrm{x} \leq 4$ & $4<\mathrm{X} \leq 6$ & $6<\mathrm{X} \leq 9$ & $9<\mathrm{X} \leq 11$ & $\mathrm{X}>11$ \\
\hline Modelo & $\mathrm{x} \leq 4$ & $4<\mathrm{X} \leq 6$ & $6<\mathrm{X} \leq 10$ & $\begin{array}{c}10<\mathrm{X} \leq \\
13\end{array}$ & $\mathrm{X}>13$ \\
\hline Saudade & $\mathrm{x} \leq 4$ & $4<\mathrm{X} \leq 6$ & $6<\mathrm{X} \leq 9$ & $9<\mathrm{X} \leq 12$ & $\mathrm{X}>12$ \\
\hline Palmito & $\mathrm{X} \leq 4$ & $4<\mathrm{X} \leq 6$ & $6<\mathrm{X} \leq 8$ & $8<\mathrm{X} \leq 11$ & $\mathrm{X}>11$ \\
\hline São Domingos & $\mathrm{x} \leq 5$ & $5<\mathrm{X} \leq 8$ & $8<\mathrm{X} \leq 11$ & $\begin{array}{c}11<\mathrm{X} \leq \\
13\end{array}$ & $\mathrm{X}>13$ \\
\hline Coronel Freitas & $\mathrm{x} \leq 4$ & $4<\mathrm{X} \leq 6$ & $6<\mathrm{X} \leq 9$ & $9<\mathrm{X} \leq 12$ & $\mathrm{X}>12$ \\
\hline Chapecó & $\mathrm{x} \leq 6$ & $6<\mathrm{X} \leq 8$ & $8<\mathrm{X} \leq 11$ & $\begin{array}{c}11<\mathrm{X} \leq \\
13\end{array}$ & $\mathrm{X}>13$ \\
\hline Ipumirim & $\mathrm{x} \leq 5$ & $5<\mathrm{X} \leq 8$ & $8<\mathrm{X} \leq 10$ & $\begin{array}{c}10<\mathrm{X} \leq \\
13\end{array}$ & $\mathrm{X}>13$ \\
\hline Passos Maia & $\mathrm{x} \leq 5$ & $5<\mathrm{X} \leq 7$ & $7<\mathrm{X} \leq 10$ & $\begin{array}{c}10<\mathrm{X} \leq \\
12\end{array}$ & $\mathrm{X}>12$ \\
\hline Irani & $\mathrm{x} \leq 6$ & $6<\mathrm{X} \leq 9$ & $9<\mathrm{X} \leq 12$ & $12<\mathrm{X} \leq$ & $\mathrm{X}>15$ \\
\hline Concórdia & $\mathrm{x} \leq 6$ & $6<\mathrm{X} \leq 8$ & $8<\mathrm{X} \leq 11$ & $\begin{array}{c}11<\mathrm{X} \leq \\
14\end{array}$ & $\mathrm{X}>14$ \\
\hline Capinzal & $\mathrm{x} \leq 6$ & $6<\mathrm{X} \leq 7$ & $7<\mathrm{X} \leq 10$ & $\begin{array}{c}10<\mathrm{X} \leq \\
12\end{array}$ & $\mathrm{X}>12$ \\
\hline
\end{tabular}

Fonte: ANA. Elaboração: Kátia Spinelli (2018).

A partir da análise dos quantis foi possível observar que a chuva mensal dentro da normalidade variou entre $106,1 \mathrm{~mm}$ a $210 \mathrm{~mm}$ entre as estações meteorológicas. Visto que o mês com pluviosidade menor ou igual a $106 \mathrm{~mm}$ na região já é considerado como um mês seco e pode favorecer a ocorrência de desastres na região.

A quantidade de dias com chuva ao mês considerados dentro da normalidade pela técnica dos quantis variou de 7 a 12 dias entre as estações meteorológicas. Visto que, os meses que possuem menos de sete dias com chuva podem gerar e/ou intensificar períodos de estiagem na Região Oeste.

Destaca-se que a má distribuição das chuvas diárias, sobretudo, concentradas em uma das quinzenas do mês, também, favoreceu o registro de desastres na região. Tais condições referem-se a dois episódios analisados, em dezembro de 1999 e janeiro de 2006.

No primeiro caso, as chuvas mensais de dezembro classificaram-se em normais ou chuvosas em grande parte das estações meteorológicas. $\mathrm{E}$, os dias com chuva ocorreram dentro da normalidade.

No entanto, verificou-se que a concentração quinzenal das precipitações em dezembro ocorreu no início do mês, sendo que $55,5 \%$ das estações meteorológicas registraram mais de $70 \%$ do volume de chuva mensal, somente, na primeira quinzena do mês.

Assim, apesar de grande parte da Região Oeste, apresentar chuva mensal dentro ou acima da normalidade em dezembro, os maiores volumes de chuva diária predominaram na primeira quinzena do mês. Sendo que, anteriormente, o mês de novembro já apresentou chuva mensal abaixo da normalidade. Essa sequência de redução de chuva favoreceu o registro de vinte e um decretos municipais de desastre por estiagem.

Em janeiro de 2006, 55,5\% das estações meteorológicas registraram chuva mensal dentro da normalidade, no entanto, verificou-se que a metade das 
estações meteorológicas registrou mais de $65 \%$ do volume mensal de chuva concentrado na segunda quinzena do mês. De modo que os meses anteriores (novembro e dezembro) já registraram chuva mensal abaixo da normalidade e com poucos ou muito poucos dias com chuva, aliados a uma primeira quinzena de janeiro menos chuvosa. Esse período de redução na precipitação provocou desastres na região, tendo 89 municípios em Estado de Emergência ou Calamidade Pública devido à estiagem.

\subsubsection{FENÔMENOS E SISTEMAS ATMOSFÉRICOS QUE FAVORECERAM OS PERÍODOS DE ESTIAGEM}

Em relação aos sistemas e fenômenos atmosféricos que favoreceram a ocorrência de estiagem, verificou-se que os períodos de estiagem foram provocados por um conjunto de sistemas atmosféricos e fenômenos, que por vezes, atuaram em conjunto. Com o propósito de analisar a atuação de cada um separadamente, quantificou-se a frequência de atuação de cada fenômeno e sistema atmosférico nos meses com estiagem.

Houve formação de pelo menos um episódio de ZCAS em 82,7\% dos meses com condições de estiagem, sendo que em $65,5 \%$ houve a formação de dois a três episódios de ZCAS.

Tal resultado evidencia que a atuação da ZCAS é importante para explicar a ocorrência de períodos de estiagem na Região Oeste catarinense. E, entram em concordância com os pesquisadores, como: Carneiro e Cavalcanti (2010), Cataldi et al. (2010) e Nogues-Paegle e Mo (1997), que evidenciaram o padrão dipolo da ZCAS, de que na Região Sul do país ocorre um déficit de precipitação sobre atuação desse fenômeno. Além disso, está em consonância com a pesquisa de Mendonça et al. (2005) que encontrou relação entre a atuação da ZCAS e a ocorrência de estiagem durante o verão na bacia do Rio Araranguá (sul catarinense).

Futuras pesquisas podem comprovar com mais clareza essa relação ao ampliar o período de análise dos dados de chuva e, verificar a persistência, intensidade, frequência e posição das ZCAS durante os períodos mais secos na Região Oeste.

Além da atuação da ZCAS, o índice da ODP esteve negativo em 72,4\% dos meses analisados, o que indica que esse fenômeno possa favorecer meses menos chuvosos na Região Oeste. Tal resultado entra em concordância com outros pesquisadores que também identificaram a atuação da ODP na redução de chuva para a Região Sul e períodos de estiagens como: Oliveira et al. (2011), Rebelo (2005), Prestes et al. (2010) e Marques (2010).

O fenômeno ENOS foi o que menos atuou durante os meses analisados. Sendo que $58,6 \%$ dos meses com condições de estiagem ocorreram sobre influência da La Niña indicados a partir do ONI. Além disso, ocorreram dois meses que apresentaram estiagem, mesmo diante da atuação de El Niño, que favorece a ocorrência de chuva mais intensas na região Sul do país.

Quando se considera o tipo de ENOS Canônico ou Modoki, verificou-se que $27,58 \%$ dos períodos de estiagem na Região Oeste ocorreram em períodos de La Niña Modoki e, 6,89\% em períodos de La Niña Canônico. Além disso, 
$20,6 \%$ dos períodos foram registrados sobre atuação de El Niño Modoki e não houve ocorrência em El Niño Canônico.

Diante disso, a ocorrência de La Niña a partir do índice ONI apresentou maior influência na formação de períodos de estiagem no Oeste de Santa Catarina. O tipo ENOS Modoki apresentou relação, porém, em menor porcentagem.

De acordo com Kayano e Andreoli (2007), o ENOS e a ODP podem atuar juntos intensificando ou enfraquecendo os efeitos do El Niño ou La Niña. Diante disso, verificou-se que $48,2 \%$ dos meses analisados tiveram influência conjunta de ODP negativa e La Niña. Ambos favorecendo as condições de estiagem verificadas na Região Oeste. Considerou-se para essa relação o ENOS a partir do índice ONI.

Além desses fenômenos de grande escala, a AAO é capaz de interferir nas condições do tempo no Hemisfério Sul. Para os meses analisados nesta pesquisa o índice da AAO foi positivo em $68,9 \%$ dos casos.

Embora, tenha ocorrido estiagem em meses com índice negativo da AAO, percebe-se que a maioria dos meses com estiagem ocorreu sobre atuação da AAO positiva. Tal resultado evidencia concordância com Oliveira (2011) e, Vasconcelos e Cavalcanti (2010), que encontraram relação entre a redução de chuva na Região Sul e o índice positivo da AAO.

Verificou-se, também, que em $41,3 \%$ dos meses analisados tiveram influência simultânea do fenômeno de La Niña pelo índice ONI, índice da ODP negativo e AAO positiva. Nesses casos, os três sistemas proporcionaram condições atmosféricas adequadas à constituição de estiagem na Região Oeste catarinense.

Apesar dos bloqueios atmosféricos não fazerem parte dessa análise, não se descarta sua influência sobre os períodos de estiagem. Visto que Sacco (2010) já identificou a relação entre a formação de bloqueios e a ocorrência de estiagens na Região Oeste. Assim, essa pesquisa demonstrou que, além dos bloqueios atmosféricos, outros fenômenos, como a ODP e a AAO, também contribuíram para a redução de chuvas e favoreceram períodos de estiagem que se tornam um risco para Região Oeste.

\section{CONSIDERAÇÕES FINAIS}

A variabilidade mensal e diária da precipitação torna-se importante para identificar e descrever os períodos de estiagem que trouxeram um impacto socioeconômico à Região Oeste catarinense.

As maiores ocorrências de desastre por estiagem na Região Oeste estiveram associadas à redução da pluviosidade de um ou dois meses anteriores ao registro por decretos municipais, ou ainda, do mês recorrente ao registro. Visto que, os períodos de estiagem que trazem impactos socioeconômicos ocorreram de novembro a abril.

As características meteorológicas que se repetiram entre os episódios e que definem as condições de estiagem foram: chuvas mensais abaixo da normalidade, configurando-se em meses secos, muito secos ou extremamente secos; aliado a poucos ou muito poucos dias com chuva durante o mês. 
Destaca-se também, que a má distribuição das chuvas diárias, sobretudo, aquelas concentradas em uma das quinzenas do mês, também, tornaram-se um perigo para a região.

Os períodos de estiagem que provocaram impactos socioeconômicos na região foram favorecidos pela influência de fenômenos e sistemas atmosféricos que, por vezes, atuaram em conjunto, como: ZCAS, ODP, La Niña e AAO.

Sendo que, a formação de ZCAS foi aquele que apresentou maior relação com os meses de estiagem analisados (novembro a abril), visto que, $82,7 \%$ dos meses tiveram atuação desse sistema. Contudo, futuras pesquisas podem desenvolver com mais ênfase essa relação entre ZCAS e estiagens ao verificar um período maior de tempo e verificar a frequência, persistência, intensidade e posição da ZCAS.

Em seguida, o índice de ODP negativo esteve presente em 72,4\% dos casos analisados de estiagem. E, o índice da AAO foi positivo em 68,9\% dos casos. O fenômeno de La Niña foi o que teve menor atuação durante os meses com estiagem, sendo que interferiu nas condições do tempo em 58,6\% dos meses.

\section{REFERÊNCIAS BIBLIOGRÁFICAS}

AMS. Drought: an information statement of the American Meteorological Society. 19 set. 2013. Disponível em: <https://www.ametsoc.org/POLICY/2013drought_amsstatement.html>. Acesso em: 26 ago. 2014.

ARMOND, N. B. Ente eventos e episódios: as excepcionalidades das chuvas e os alagamentos no espaço urbano do Rio de Janeiro. 2014. 240f. Dissertação (Mestrado em Geografia) - Faculdade de Ciência e Tecnologia da Universidade Estadual Paulista Júlio de Mesquita Filho - UNESP. Presidente Prudente.

ASHOK, K.; BEHERA, S. K.; RAO, S. A.; WENG, H.; YAMAGATA, Y. EI Niño Modoki and its possible teleconnection. Journal of Geophysical Research, v. 112, p. 1-27, 2007.

CATALDI, M.; ASSAD, L. P. de F.; JUNIOR TORRES, A. R.; ALVES, J. L. D. Estudo da influência das anomalias da TSM do Atlântico Sul Extratropical na região da confluência Brasil Malvinas no regime hidrometeorológico de verão do sul e sudeste do Brasil. Revista Brasileira de Meteorologia, v. 25, n.4, p. 513-524, 2010.

CARNEIRO, G. M. ; CAVALCANTI, I. F. A. Características da convecção associada à variabilidade intrassazonal: comparação entre resultados do MCGA CPTEC/COLA e observação. Revista Brasileira de Meteorologia, v. 25, n. 4, p. 525- 534, 2010.

CARVALHO, L. M. V. de; JONES, C. Zona de Convergência do Atlântico Sul. CAVALCANTI, I.F.A. ; FERREIRA, N. J.; SILVA, M. G. A. J.; DIAS, M. A. F. da (org.). Tempo e Clima no Brasil. São Paulo: Oficina de texto, 2009, p.280-296.

CASTRO, A. L. C. Manual de desastres naturais. Brasília: Ministério do Planejamento e Orçamento, Secretaria Especial de Políticas Regionais, Departamento de Defesa Civil,1996. 
CASTRO, A. L. C. Manual de desastres: desastres naturais. Brasília: Ministério da Integração Nacional, 2003. 174 p.

CAVALCANTI, I. F. A.; AMBRIZZI, T. Teleconexões e suas influências no Brasil. CAVALCANTI, I. F. A.; FERREIRA, N. J.; SILVA, M. G. A. J.; DIAS, M. A. F. da. (Org.). Tempo e Clima no Brasil. São Paulo: Oficina de texto, 2009, p. 317-335.

CERA, J. C.; FERRAZ, S. E. T.; BENDER, F. D. Influência da oscilação decadal do Pacífico e as mudanças no regime de chuva do Rio Grande do Sul. Revista Ciência e Natureza. Ed. Especial - Micrometeorologia (2009). Disponível em: <http://cascavel.ufsm.br/revista_ccne/ojs/index.php/cienciaenatura/article/view File/410/321>. Acesso em: 4 jun. 2013.

DOUBRAWA, A. A crise de água e sua possível relação com os parcos remanescentes florestais na região oeste do estado de Santa Catarina. 2007. 178 f. Dissertação (Mestrado em Engenharia Ambiental). Universidade Regional de Blumenau - FURB, Centro de Ciências Biológicas, Blumenau.

GRIMM, A. M. Variabilidade interanual do clima no Brasil. In: CAVALCANTI, I. F. A. et al. (Org.). Tempo e Clima no Brasil. São Paulo: Oficina de texto, 2009, p. $353-374$.

GONÇALVES, E. F.; MOLLERI, G. S. F.; OLIVEIRA, C. A. F. de; MURARA, P. G. Estiagem. In: HERRMANN, M. L. de. P. (Org.). Atlas de desastres naturais do estado de Santa Catarina: período de 1980 a 2010. 2. edição atualizada e revisada. Florianópolis, SC: Instituto Histórico e Geográfico de Santa Catarina, Cadernos Geográfico, 2014.

HERRMANN, M. L. de. P. (Org.). Atlas de desastres naturais do estado de Santa Catarina: período de 1980 a 2010. 2 o edição atualizada e revisada. Florianópolis, SC: Instituto Histórico e Geográfico de Santa Catarina, Cadernos Geográfico, 2014.

HERRMANN, M. L. de. P.; ALVES, D. B. As principias consequências negativas provocadas pelas adversidades atmosféricas no estado de Santa Catarina. In: HERRMANN, M. L. de. P. (Org.). Atlas de desastres naturais do estado de Santa Catarina: período de 1980 a 2010. 2 o edição atualizada e revisada. Florianópolis, SC: Instituto Histórico e Geográfico de Santa Catarina, Cadernos Geográfico, 2014.

HISDAL, H.; TALLAKSEN, L. M. (Org.). Drought event definition. N. 6. December 2000. Disponível em: <http://www.hydrology.unifreiburg.de/forsch/aride/navigation/publications/pdfs/aride-techrep6.pdf $>$.

Acesso em: 12 out. 2014.

JOINT INSTITUTE FOR THE STUDY OF THE ATMOSPHERE AND OCEAN. PDO index. Disponível em: <http://jisao.washington.edu/pdo/PDO.latest>. Acesso em: 10 fev. 2014.

KAYANO, M. T; ANDREOLLI, R. V. Relations of South American summer rainfall interannual variations with the Pacific Decadal Oscillation. In: International Journal of Climatology. 2007. Disponível em: <http://mtcm15.sid.inpe.br/col/cptec.inpe.br/walmeida/2004/11.23.15.19/doc/Kayano_rela tions.pdf>. Acesso em: 4 jun. 2010. 
MARENGO, J. A.; AMBRIZZI, T.; SOARES, W. R. Jato de baixos níveis ao longo dos Andes. In: CAVALCANTI, I.F.A. et al. (org.). Tempo e Clima no Brasil. São Paulo: Oficina de texto, 2009, p.169-180.

MATTEDI, M. A.; BUTZKE, I. C. A relação entre o social e o natural das abordagens de hazards e de desastres. Ambiente \& sociedade, ano IV, $\mathrm{n}^{\circ} 9,2^{\circ}$ semestre de 2001, p. 1-22.

MENDONÇA, M.; MONTEIRO, M.; MARQUETE, V. A. Variabilidade da precipitação, estiagens e produção agrícola na bacia hidrográfica do Rio Araranguá/SC, entre 2001-2004. Anais... XI Simpósio Brasileiro de Geografia Física Aplicada, 05-06 set 2005. São Paulo, p. 5327-5336.

MENDES, M.C.D ; TRIGO, R. M. ; CAVALCANTI, I. F. A. ; DACAMARA, A. C. Bloqueios atmosféricos de 1960 a 2000 sobre o oceano Pacífico Sul: impactos climáticos e mecanismos físicos associados. Revista Brasileira de Meteorologia, v. 20, n. 2, p.175-190, 2005. Disponível em:<http://www.rbmet.org.br/port/revista/revista_dl.php?id_artigo=125\&id_ar quivo=162 >. Acesso em: 20 jan. 2011.

MINUZZI, R. B. Chuvas em Santa Catarina durante eventos de El Niño oscilação sul. Revista Geosul, v. 25, n. 50. Florianópolis: Editora da UFSC, jul./dez. 2010, p. 107-127.

MINUZZI, R.B. Variabilidade no regime da chuva em Santa Catarina durante diferentes tipos de ENOS. Agrometeoros, Passo Fundo, v.26, n.1, p.113-122, jul. 2018.

NIMER, E. Climatologia do Brasil. Rio de Janeiro: IBGE, 1979, p. 195-263.

NATIONAL OCEANIC AND ATMOSPHERIC ADMINISTRATION. Antartic Oscillation (AAO). Disponível em: <http://www.cpc.ncep.noaa.gov/products/precip/CWlink/daily_ao_index/aao/aa o.shtml>. Acesso em: 30 fev. 2014.

NOGUÉS - PAEGLE, J. ; MO, K. C. Alternating Wet and Dry Conditions over South America during Summer. Monthy Weather Review. Fev. 1997, p. 279295.

OLIVEIRA, F. G. Relações entre o índice de oscilação antártica e as vazões na bacia hidrográfica do Rio Uruguai, Região Sul do Brasil. 2011. 83 f. Dissertação (Mestre em Ciências). Centro das Ciências da Matemática e da Natureza, Universidade Federal do Rio de Janeiro, Rio de Janeiro, 2011.

REBELLO, E. R. G.. As Oscilações Decadais do Pacífico e suas possíveis influências no estado do Rio Grande do Sul. Anais... XIV Simpósio Brasileiro de Meteorologia, 2006, Florianópolis - SC, CBMET, 2006.

SACCO, F. G. Configurações atmosféricas em eventos de estiagem de 2001 a 2006 na mesorregião Oeste Catarinense. Maio 2010. 107 f. Dissertação (Mestrado em geografia). Departamento de Pós-Graduação em Geografia, Universidade Federal de Santa Catarina, Florianópolis, 2010.

SANTOS, I. A., FRANCO, N. J. N. Uso do índice mensal da Oscilação Antártica para avaliação de algumas interações com a circulação troposférica na América do Sul e Oceanos Próximos. In: Congresso Brasileiro de Meteorologia, 16, 2010. 
A Amazônia e o Clima Global. Belém: Sociedade Brasileira de Meteorologia, p. 15 .

SILVESTRI, G. E., VERA, C. S. Nonstationary Impacts of the Southern Annular Mode on Southern Hemisphere Climate. Journal of Climate, 22, 2009, p. 61426148.

PRESTES, et al. Relações entre a Oscilação Decadal do Pacífico e a Variabilidade da Precipitação em Porto Alegre, RS. Anais... XVI Congresso Nacional de Meteorologia. 13 a 17 de setembro de 2010. Belém - Pará. Disponivel em: < http://www.cbmet2010.com/anais/ >. Acesso em: 28 de fevereiro de 2011.

SPÍNDOLA, M. A.; NODARI, E. S. As estiagens no oeste catarinense sob a perspectiva da história ambiental. In: $2^{\circ}$ SIMPÓSIO INTERNACIONAL DE HISTÓRIA AMBIENTAL E MIGRAÇÕES, 17 a 19 set. 2012, Florianópolis. Anais... Florianópolis: LABIMHA, 2012, p. 2691-2715.

SPINELLI, K. Estiagem e a vulnerabilidade social no Oeste de Santa Catarina no período de 1999 a 2012. 309f. Tese (Doutorado em Geografia), Departamento de Pós-Graduação em Geografia, Universidade Federal de Santa Catarina, Florianópolis, 2018.

STRECK N. A et al. Associação da variabilidade da precipitação pluvial em Santa Maria com a Oscilação Decadal do Pacífico. Revista Pesquisa agropecuária brasileira, Brasília, v. 44, n. 12, dez. 2009, p.1553-1561.

TEDESCHI, R. G.; CAVALCANTI, I. F. A. Influência do ENOS Canônico e Modoki na precipitação da América do Sul. In: XVI Congresso Brasileiro de Meteorologia, 13 a 17 set. 2010, Belém. Anais...Disponível em: <http://www.sbmet.org.br/cbmet2010/artigos/354_23512.pdf >. Acesso em: 25 ago. 2019.

VASCONCELOS, F. C.; CAVALCANTI, I. F. A. Relação entre a Oscilação Antártica e a América do Sul, oceano Atlântico e Pacífico adjacente em novembro. Anais... XVI Simpósio Brasileiro de Meteorologia, 13 a 17 set. 2010, p. Disponível em: <http://www.sbmet.org.br/cbmet2010/artigos/133_68415.pdf>. Acesso em: 29 jul. 2017.

XAVIER,T.M.B. ; XAVIER, A.F.S. Caracterização de períodos secos ou excessivamente chuvosos no estado do Ceará através da técnica dos quantis: 1964 - 1998. Revista Brasileira de Meteorologia, v 14, n.2, 63-78, 1999.

WILHITE D. A.; HAYES, M. J.; KNUTSON, C. L. Drought preparedness planning: building institutional capacity. In: WILHITE, D. A. Drought and water crises. Science, technology, and management issue. Series II. Boca Raton, FL: Taylor and Francis, 2005, p. 93-136 